\title{
TAILOR-MADE DESIGN GUIDELINES FOR HUMAN FACTORS AND USABILITY FOR MEDICAL DEVICE APPLICATION: A PROPOSED METHODOLOGY
}

\author{
Nagarajan, Kamya; Silva, Arlindo \\ Singapore University of Technology and Design
}

\begin{abstract}
With increasing level of advancement and complexity in medical devices, there is a need for methodology, tools and techniques in practice to integrate Human Factors and Usability (HF/U) elements in design due to its increasing diversity of users and rapidly changing interface types. This paper proposes a methodology to develop a tailor-made HF/U design guidelines for medical device development with various sources and to develop heuristics for evaluation and score the product usability throughout the development process.
\end{abstract}

Keywords: User centred design, Design methodology, Evaluation, Early design phases

Contact:

Nagarajan, Kamya

Singapore University of Technology and Design

Engineering Product Development

Singapore

kamya_nagarajan@mymail.sutd.edu.sg 


\section{INTRODUCTION}

Medical device design is complex because of its varied healthcare setting, user profiles, and ailments. The transition to decentralised health-care model and needs of multiple types of users to be considered during design mainly differentiates medical devices to other human factors domains. Human Factors in medical device design is drawing more attention since FDA's Draft Guidance to applying Human Factors and Usability (HF/U) engineering to optimize medical device design in 2011. Contrastingly, knowledge in Human Factors and Usability engineering has been proliferating in other domains such as consumer electronics, Human-Computer Interaction, automotive and aviation to constantly improve safety and user satisfaction. Due to the recent attention received by medical device industries, they are unlikely to have the resources to employ Human Factors consultancies or staff with specific expertise. But this should not be a barrier to adopting Human Factors and Usability principles in their designs (Martin et al., 2008).

Conducting user research and testing at regular intervals throughout the development process are some Human Factors practices that medical device industries are slow to adopt compared to other industries. This is due to its complexity in interviewing current users and observing them in real environments, e.g. when designing products for patients with rare conditions or for physicians with specific training which make it difficult to recruit/engage end users for research (Foster et al., 2017). In certain phases of product development, it may be difficult to obtain users, and developers may have to consider using proxies in place of real users particularly in early design process and perform product evaluations inhouse and hence, ensures that confidential details of new technologies are not compromised (Martin et $a l ., 2008)$. Shah and Robinson (2007) state that key barriers to user involvement are the demands thus generated for extra resources, mainly in terms of time and money involved and their relationship to the user characteristics, availability, cooperation, preparation, and motivation, in the context of any given product.

A guideline document develops a shared language and promotes consistency among multiple design engineers in terminology usage, appearance, and action sequences. The early Apple and Microsoft guidelines, which were influential for desktop interface designers, have been followed by dozens of guideline documents for web and mobile devices (Schneiderman et al., 2017). A relevant set of design guidelines for medical device enable manufacturers integrate HF/U right from the early design phase, which is the most flexible phase of product development. This will help practitioners to set reasonable requirement specifications, select concepts, evaluate prototypes, prepare for testing and so on early in process of development. Having an initial draft of $\mathrm{HF} / \mathrm{U}$ guidelines in the early in product development helps cross-functional team to be in-line with the target. This, in-turn reduces design iteration and team conflicts during the critical stages of product development, when time and cost matters the most.

Vincent and Blandford (2011) discovered issues in current medical device usability design guidance methods. In their interview study with medical device design practitioners, developers were often unaware of guidance or felt it to be inappropriate or inadequate. A tailor-made HF/U design guideline is required to aid industries address the constraints to apply HF/U research findings into practice.

Current Human factors assessment methods such as focus groups, usability testing, think aloud can be done only when there is a tangible device developed. Bringing in real users frequently to assess a product usability is a time consuming, expensive and exhausting process. Thus, there is a need for a technique that can assess the design periodically even before there is a tangible device in place.

Inspiration of this paper has come from our experience in interacting with R\&D teams in a medical device company. There seems to be a need of methodology that captures HF/U elements to maintain a quantifiable document that represents the design progress throughout the development process. In this paper, we propose a methodology to develop HF/U design guidelines that considers knowledge within and outside the organization, where there is a possibility to cross-pollinate ideas and hence, use the guidelines to aid design assessment even before user involvement.

\section{METHODOLOGY}

The methodology proposed in this paper comprises of literature review and learnings from case study on potential sources of information that could help develop $\mathrm{HF} / \mathrm{U}$ design guidelines considering contents of user feedback, lessons learned, expert recommendations, learnings from other similar industry. 
This study includes developing HF/U design guidelines, using the design guidelines to develop a set of heuristics for evaluation and hence using design guidelines to create rubrics for periodic usability testing in the process of product development.

Using generic design standards or guidelines can be interpreted and used in different ways depending on the expertise of human factors and design engineer, hence there is a possibility of inept use of guidelines. A tailor-made design guideline relies less on the expertise of design team in human factors knowledge and acts tangible support to HF/U engineers to advocate for design decisions. We propose a method of developing HF/U design guidelines analysed from various sources of information within and outside the medical device industry as shown in Figure 1. Further in this section, we consider value of the sources seen by previous studies in the literature.

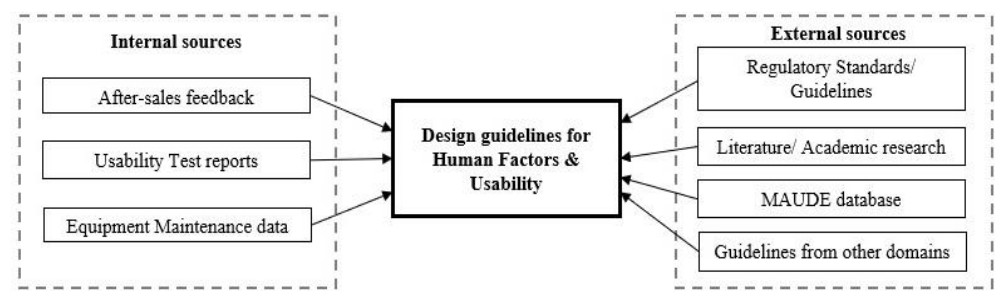

Figure 1: Sources of information or developing guidelines

\subsection{Information from internal sources}

One of the challenges of medical device industries is recruiting end-users for research (Foster et al., 2017). This adds on other related challenges like bringing the users on regular intervals of product development, creating an actual environment where the device will be used, quickly generating solution for a design decision.

There are some rich sources of information representing real usability problems are available within the organization which is less valued for $\mathrm{HF} / \mathrm{U}$ input to develop new products. Guidelines developed from company's own customer feedback and own products' lesson-learnt will be emphatically agreed upon by various teams within organization unlike other guidelines where the context of practice is questionable and seen as a constraint (Shorrock and Williams, 2016).

\subsubsection{After sales feedback}

A case study by Kuijk et al., (2007) with 5 product development companies show that after sales feedback can be a very valuable source of information during initial design and throughout the development process. Analysing after-sales feedback information helps understand and mitigate issues with existing products and feeds into new product development which corresponds to the findings of Kuijk et al., (2007).

Ouden, (2005) points out that customer service teams might not be equipped enough to process usability issues, as their classification system of complaints mostly focuses on technical errors. To enable effective information gathering, after sales team must be trained and be equipped with template that collects usable information from customers (through customer service feedback, complaints or field studies). Effective communication between the sales team and the design team plays a vital role here. This in line with the findings of Kuijk et al., (2007) which says that being housed in the same location allows customer support department to discuss design, specially to indicate early-on that a certain design choice will lead to increased customer support. Figure 2 Shows the stages of how aftersales information can be processed for input to develop design guideline.

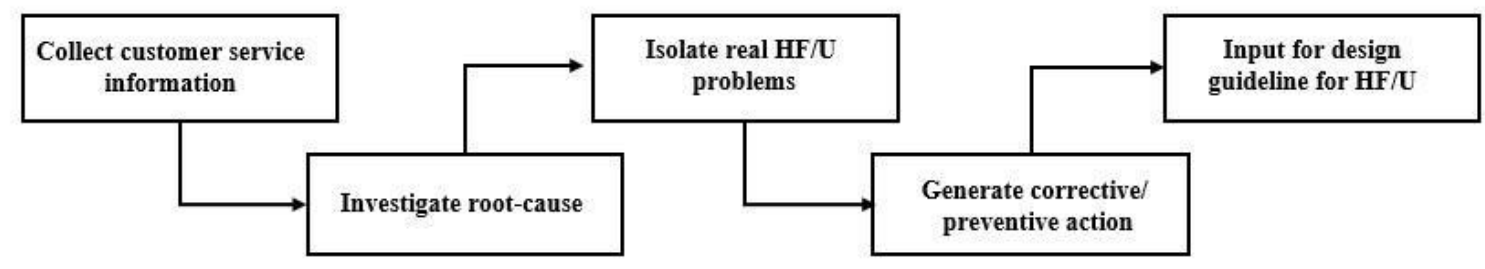

Figure 2: Extracting design input for $\mathrm{HF} / \mathrm{U}$ guideline from after-sales information 


\subsubsection{Usability test reports}

Usability tests once conducted by organization for previous projects could reep benefits even for future projects. Reports of usability tests conducted for previous products within the medical device organization contains user insights on design prototypes(formative) and near to final designs(summative). Exploratively, we believe information from usability test reports existing in the organization could contribute to develop design guidelines, as it directly includes findings of user-device interaction in the process.

\subsubsection{Equipment maintenance information}

'No fault found (NFF)' or 'problem cannot be replicated' reports when further investigated discovered design faults, specifically usability problems in design. Through interviews, heuristic evaluation and usability testing revealed that usability issues were the root cause for a significant portion of NFF reports (Flewwelling et al., 2014). Most service and maintenance information are focused on device faults and do not capture the user aspects. Like after-sales information, the format that collects maintenance information needs a template that can capture user information required for further investigation.

\subsection{Information from external sources}

Information outside the industry gives numerous insights and room to cross-pollinate ideas. Since, these are already established set of guidelines, it gives confidence to practitioners to take lead for design decisions with latest findings in parallel technologies.

\subsubsection{Regulatory standards/guidelines}

There are regulatory standards and guidelines developed for medical devices such as AAMI HE74, AAMI HE75, IEC 60601, ISO 14971(2000), IEC 62366, and so on. Some of these standards are followed by medical device companies as they are mandatory requirements to be met depending on the market regulations. The guidelines come from multiple resources such as other industries, academic papers and books. The challenge practitioners have currently is to use the guidelines specific to the application they need. The guidelines do not contain details such as anthropometric information, type of disabilities, which makes it ambiguous to put in practice. However, the effectiveness of these guidelines varies depending on organizations' experience and expertise in using them.

\subsubsection{Literature/academic research findings}

Literature work covers both academic and case studies from industries, where the direction for product specification and design decisions can be obtained. The advantage of using literature findings for design guidelines over other resources is that, literature work covers empirical studies on specific design element and gives details of experimental set-up and user background and accompanying limitations of the studies.

\subsubsection{MAUDE database}

MAUDE (Manufacturer and User Facility Device Experience) information from FDA (U.S. Food and Drug Administration) database is open to public providing information about medical device adverse events and product problems submitted by manufacturers, importers and device user facilities in the past 10 years. Ensign and Cohen (2017) have done a detailed study on MAUDE database website regarding its content, structure and technical consideration to manage information from the database and mention that MAUDE is a valuable database for some actionable analytics and would provide a practical insight for design guidelines.

The reports in MAUDE database are categorized based on problem type, product class, event type, brand name and dates of report received as shown in Figure 3 and is helpful in finding specific adverse event. 


\section{MAUDE - Manufacturer and User Facility Device Experience

\author{
- FDA Home 0 Medical Devices 0 Databases
}

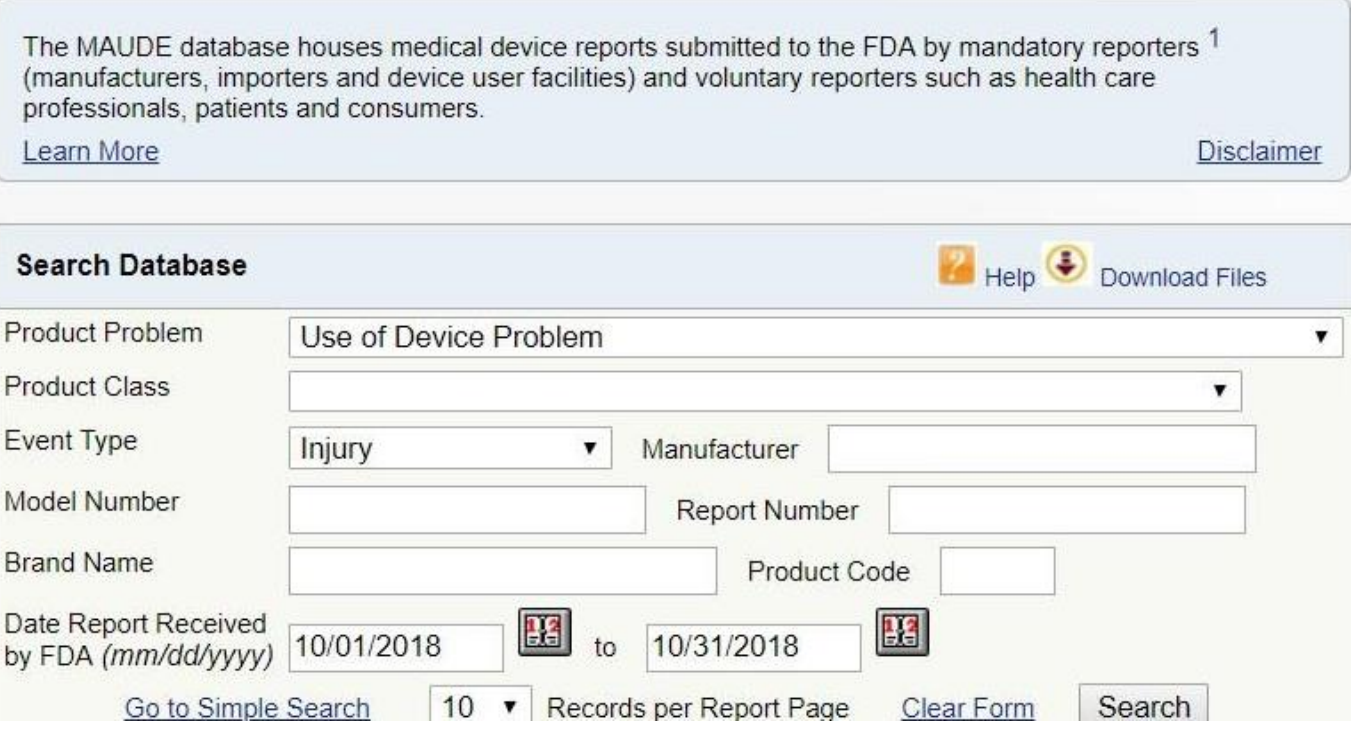

Figure 3: Screenshot of MAUDE database to search specific report

\subsubsection{Guidelines from other domains}

There are industry guidelines developed specifically for HF/U by many other domains which can be useful source of information for developing own design guidelines. Some industry guidelines available as open access, for example are FAA Human Factors design guide, NHTSA Human Factors Design guidance for Driver-Vehicle Interfaces, Google material, Apple guidelines, Microsoft mobile usability guidelines, etc. Some of these guidelines are developed based on the industries experience and established as a practice to enable internal and external stake-holders to develop products harmoniously. Information from developed design guidelines of other domains adds a perspective on how an entity of a product is dealt in other domains and enables cross-pollination of ideas.

\subsection{Using $\mathrm{HF} / \mathrm{U}$ design guidelines as key for $\mathrm{HF} / \mathrm{U}$ assessments}

\subsubsection{Developing heuristics for product assessment}

Conducting heuristics evaluation is a very common HF/U method of evaluating a product within the organization. Having well-defined set of heuristics are required when the evaluation method must capture most $\mathrm{HF} / \mathrm{U}$ issues irrespective of evaluator. Using usability guidelines, developed by their own work or others, to convert into heuristics has been implemented in other applications such as Human Computer Interaction (Gummussoy, 2016; Hoehle et al., 2016), Human-Robot Interaction (Adamides et al., 2014). Heuristics are developed in various methods and has been reviewed by Quinones and Rusu (2016), and they found that 5 studies developed heuristics using design guidelines or principles/recommendations and covers domains in building design, interactive television, IT security management, digital learning games and mobile launchers for elderly. Hence, the past works provide motivation to substantiate the idea of using design guidelines to create heuristics for medical device assessment.

\subsubsection{Creating rubrics for product $H F / U$ assessment:}

Scoring HF/U will show the progress in terms of HF/U of a design and product. Albert and Tullis (2013) in their book mention that "Usability metrics are the only way to really know if the desired improvements have been realized. By measuring and comparing the current with new, improved product and evaluating the potential improvement, you create win-win situation. Usability metrics are key ingredients in calculating ROI (Return of Investment)". Quantifying usability and its aspects such as user 
experience, user satisfaction has proved to have benefits in Human-Computer Interaction (HCI). Hoehle et al. (2016) developed an instrument to scale mobile application usability through Microsoft's mobile usability guidelines. (Shrestha, Abdinnour-Helm and Chaparro, 2008) used Analytical Hierarchical Process to create a single usability score for a website interface; Sauro and Kindlund (2005) used standardization techniques from Six Sigma, to propose scalable process for standardizing disparate usability metric. The benefits of having usability metrics from the above studies can be explored to apply in medical device as well. This create a quantifiable goal for designers and enable awareness of the usability status of the product at any given time of development.

\section{CASE STUDY: NEED OR TAILORING HF/U DESIGN GUIDELINE}

There was a need identified through literature that practitioners are unable to effectively use the current standards, guidelines for usability to set design specification for medical device and other interfaces. Also, there was a lack of resources and expertise in integrating HF/U throughout the product development process. The similar need was discovered while working with practitioners at a well-known medical device company, while working on developing $\mathrm{HF} / \mathrm{U}$ design guideline for a touchscreen interface in a medical device. The interface design of medical devices requires tailoring based on the type of users, environment of operation and any partnering device during the medical device operation as represented in Figure 4.

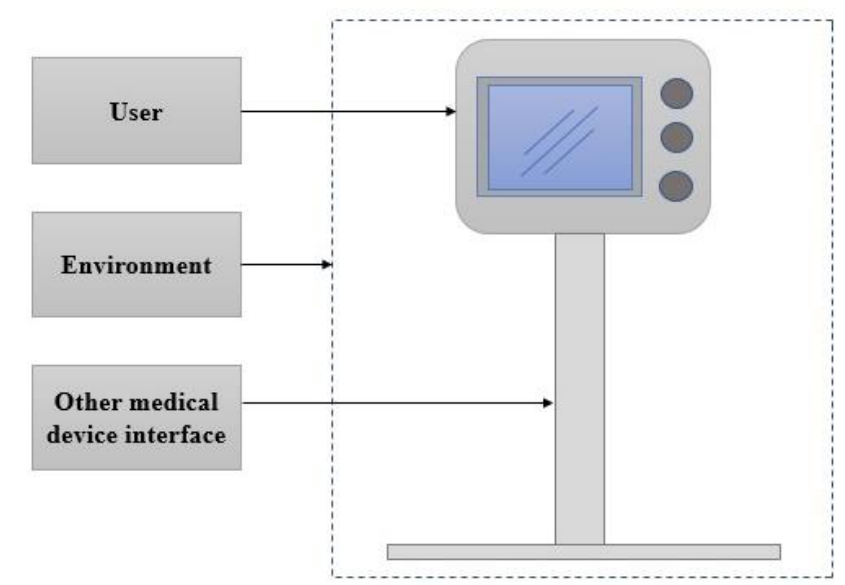

Figure 4: Schematic of medical device and interface design factors

Touchscreens are becoming a predominant way to interact with all kinds of devices, including medical devices. The user needs and design considerations are different for medical devices compared to other personal (mobile phones, tablets, etc) or public touchscreen interfaces (check-in kiosk, ticketing interface, etc).

The users of medical devices are much varied in terms of profession, relevant knowledge, experience in use physical abilities, age, etc. For instance, the users of a single medical device for a therapy could be

1. Therapist

2. Clinicians

3. Nurses

4. Patients with or without disabilities

5. Caretakers

6. Equipment trainers

As much diverse are the users of medical device, so is the diversity in their needs. A few needs to be considered which are unique to the design of medical devices are

1. Use of gloves while operating the device

2. Ease of cleaning(sanitizing)

3. Type of procedure the device will be used for (Surgeries, rehabilitation, daily-life, etc)

4. Impact of interaction error during the medical procedure

5. Additional medical condition of patient apart from the one treated using the medical device

6. Any other medical devices that are to be connected or worked in parallel with.

There were various elements of use of a touchscreen considered during design guideline development. For instance, while considering a key touchscreen element, "button" design, there were many aspects 
to be considered such as button dimension, spacing between buttons, feedback type, text type and style on the button, the graphic design of the button which visually differentiates itself from the background and appears intuitively as a touch button.

It was challenging to find similar work in literature which could be considered directly for developing guidelines for medical device application. Since the user needs and environment device environment for medical devices are different from other touchscreen device, there was less confidence in adapting the suggested design in literature and guidelines of other touchscreen devices., although there were studies done on touchscreen button design in different contexts. Touchscreen button size and spacing recommendations (for example) were searched in literature and different device applications and different results were found as shown in the Figure 5. some of the findings were reported specifically for Elderly Participants (EP) as well.

\begin{tabular}{|l|c|c|c|c|}
\hline \multicolumn{1}{|c|}{ Reference } & $\begin{array}{c}\text { Target Size } \\
\text { (in } \mathbf{~ m m} \text { ) }\end{array}$ & $\begin{array}{c}\text { Spacing (in } \\
\mathbf{m m} \text { ) }\end{array}$ & $\begin{array}{c}\text { Type } \\
\text { inches) }\end{array}$ \\
\hline Tao et al (2018) & $>=17.5$ & 3 & Touchscreen computer & 23 \\
\hline Kim et al(2012) & $9,11.2$ & No effect & Tablet PC & 10.1 \\
\hline Kim et al(2014) & 17.5 & Not available & Driver interface touchscreen & 17 \\
\hline Colle \& Hiszem(2004) & 20 & 1 & Standing at Kiosk & 12.1 \\
\hline $\begin{array}{l}\text { Hwangbo et al(2013) } \\
\text { for EP }\end{array}$ & 12 & 1 & Handphone & Not available \\
\hline Jin et al(2007) for EP & $16.5,19$ & 6.35 & LCD touchscreen & 17 \\
\hline Sun et al(2007) & $>=10.6$ & $1.3-5.3$ & Touchscreen for firefighters & Not available \\
\hline
\end{tabular}

Figure 5: Examples of related literature findings on touchscreen button size and spacing.

\section{FINDINGS}

The literature findings on current use of available guidelines and the industry requirement for design guideline were similar. It was evident that there is a strong need for a tailor-made design guideline which is easy to understand, use and verify with frequently changing design of medical device, like any other product development process.

Challenges:

Challenges encountered during the case study is the key motivation of this paper. The challenges were 1. Getting most relevant information to develop as a guideline.

2. Use those sources of information to convince design team to make a user-centric design choice.

3. Tracking the design progress in-terms of $\mathrm{HF} / \mathrm{U}$ throughout the development process.

4. There was no quantifiable HF/U goal for designers to aim for, like in product quality score targets.

Opportunities:

Various opportunities appeared during the case study of developing design guidelines such as

1. Learning from similar industries such as HCI, consumer electronics which comes with an advantage that users of medical devices have already been using some of computer, mobile, and consumer electronics devices and the expectation of how a device element performs must be in-line with other devices they encounter day-to-day.

2. Using existing internal information coming from real use cases as input for developing new products. 3. Develop a methodology to create tailor-made design guidelines that the design team can rely on and be customized for other design guidelines within the domain.

4. Use the developed guidelines to quantify usability of design.

\section{DISCUSSION}

This methodology is an outcome of a case-study experience while the authors encountered a situation during the process of developing design guidelines for a touch-screen interaction for a medical device in the context of HF/U. While there are many other design guidelines available within industries, we propose a methodology that the practitioners can rely on. Customer reports can be analysed using qualitative content analysis. Studies from literature show that content analysis is used successfully in developing design guidelines. (Hoehle et al., 2016, Jones et al., 2018). 


\subsection{Benefits and limitation of the methodology}

Vincent and Blandford (2011), based on the interviews conducted summarized that good communication practices and development of common perspective were essential for implementing user-centric techniques. Developing and using tailor-made HF/U design guideline will not just practice the available relevant knowledge but also helps maintain consistency among products and enables collaborative working practices. Usability score communicates real time status of the device design and rationale behind design decisions as there are one or more non-HF/U engineering team which makes the design choice. Since the methodology considers existing real issues of company's own products, refers relevant standards, literature and MAUDE database, it gives a panoramic perspective of useful information that already exists.

The proposed methodology has limitations. The design guidelines do not remain fixed once developed in the early stages of the product development. It needs to be reviewed periodically to adapt to the changes in device features, collected internal information of usability issues, and other changing information from external sources. Implementation of this methodology must consider current process of product development and the quality of available information required to develop guidelines. Time taken to develop the guidelines must be managed as the implementation and validation must not disturb the current product's development timelines and deliverables.

It is pertinent to note that Cantamessa et al., (2016) in their study emphasise the needs of multiplestakeholders. Needs identification and requirement specification of medical device must consider multiple stake-holders instead of designing just around user (single stakeholder) needs. In this methodology, we focus on design guidelines for human factors and usability for medical device designers to consider requirement specification from $\mathrm{HF} / \mathrm{U}$ perspective.

\subsection{Future work}

Information coming from the various sources mentioned can be overwhelming and there is a need for standard procedure to analyse and develop into a design guideline. Individual category of information might not address most HF/U issues, but a set of guidelines developed out of the above-mentioned sources is expected to prevent most $\mathrm{HF} / \mathrm{U}$ issues in the current product.

To validate the proposed method, our future work will focus on a scoring strategy for product usability that can be used to compare products within the organization which in-turn will help scoring reference devices during benchmark activities. Ease of implementation, validity and effectiveness of the method is expected to be done through a case-study with an actual medical device development process, which will eventually lead to a revised version of the proposed methodology. The validity of created rubrics is to be compared with real user testing score, which will be conducted during formative and summative tests. As a quote from Dennis Wixon says, "In my opinion, a case study approach is both the only practical way to produce a body of knowledge for applied usability, and the most effective."

\section{CONCLUSION}

The contribution of this paper is on a methodology to develop tailor-made human factors and usability design guidelines. Further, using the design guidelines to develop heuristics and scoring product usability in the context of medical device application. The elements of the proposed methodology take inspiration from existing literature and experience working with a well-known medical device company. The case-study helped us understand the need and foresee benefits of implementing the proposed methodology to better manage the integration of HF/U into product development process. Although the proposed methodology aids to capture usability aspects right from early design even before involving users, it is not an alternative to real user testing as end-user testing is imperative to reveal any remaining problems in design.

\section{REFERENCES}

Adamides, G., Christou, G., Christos, K., Michalis, X. and Hadzilacos, T. (2015), "Usability Guidelines for the Design of Robot Teleoperation: A Taxonomy”. IEEE Transactions On Human-Machine Systems, Vol. 45 No. 2, pp. 256-262. http://doi.org/10.1109/THMS.2014.2371048

Albert, W. and Tullis, T. (2013), "Measuring User Experience”, Morgan Kaufmann, May 23, 2013. Vol. 2 No. 1, pp. 123-130, Sage Publication. http://doi.org/10.1177/2327857913021024 
Colle, H.A. and Hiszem, K.J. (2004), "Standing at a kiosk: Effects of key size and spacing on touch screen numeric keypad performance and user preference”. Ergonomics, Vol. 47 No. 13, pp. 1406-1423. http://doi.org/10.1080/00140130410001724228

Cantamessa, M., Montagna, F. and Cascini, G. (2016), "Design for innovation - A methodology to engineer the innovation diffusion into the development process", Computers in Industry, Vol. 75, pp. 46-57. http://doi.org/10.1016/j.compind.2015.10.013

Ensign, L.G. and Cohen, K.B. (2017), “A Primer to the Structure, Content and Linkage of the FDA's Manufacturer and User Facility Device Experience (MAUDE) Files”. eGEMs (Generating Evidence \& Methods to improve patient outcomes),Vol. 5 No. 1, p. 12. http://doi.org/10.5334/egems.221

Flewwelling, C.J, Easty, A.C., Vincente, K.J., and Cafazzo, J.A. (2014), “The use of fault reporting of medical equipment to identify latent design flaws". Journal of Biomedical Informatics, Vol. 51, pp. 80-85. http://doi.org/10.1016/j.jbi.2014.04.009

Foster, B.L., Branaghan, R.J, Barker, D., Conahue, J. and Rundus, M.D. (2017), "What can medical device human factors learn from other industries?", In proceedings of International Symposium on Human Factors and Ergonomics in Health Care, Vol. 6, No. 1, pp. 183-184.

Gummussoy, C.A. (2016), "Usability Guideline for Banking Software design”, Computers in Human Behaviour. Vol. 62, pp. 277-285. http://doi.org/10.1016/j.chb.2016.04.001

Hoehle, Hartmut; Aljafari, Ruba and Venkatesh, Viswanath (2016), "Leveraging Microsoft's mobile usability guidelines: Conceptualizing and developing scales for mobile application usability", International Journal of Human Computer Studies, Vol. 89, pp. 35-53. http://doi.org/10.1016/j.ijhcs.2016.02.001.

Hwangbo, H., Yoon, S.H., Jun, B.S., Jin, Y.S. and Ji, Y.G., “A Study of Pointing Performance of Elderly Users on Smartphones”, International Journal of Human-Computer Interaction, Vol. 29 No. 9, pp. 604-618. http://doi.org/10.1080/10447318.2012.729996

Jin, Z.X., Ploucher, T. and Kiff, 1. (2007), “Touch Screen User Interfaces for Older Adults: Button Size and Spacing”. In Proceedings of International Conference on Universal Access in Human-Computer Interaction, pp. 933-941. http://doi.org/10.1007/978-3-540-73279-2_104

Jones, J., Bubric, K., Biesbroek, S. and Laberge, J. (2018), "Human Factors Guidelines for the Design of Mobile Medical Environments". Ergonomics in Design: The Quarterly of Human Factors Applications, Vol. 26 No. 3, pp. 9-16. http://doi.org/10.1177/1064804617744975

Kim, H., Kwon, S., Heo, J. and Chung, M.K. (2014), "The effect of touch-key size on the usability of In-Vehicle Information Systems and driving safety during simulated driving", Applied Ergonomics. Vol. 45 No. 3, pp. 379-388. http://doi.org/10.1016/j.apergo.2013.05.006

Kim, J.M., Ishibashi, K. and Iwanaga, K. (2012), "Effect of Sizing and Spacing of Touchscreen Buttons of Performance on Number input Task: Comparison Between Younger and Older Adults" The Science of Design, Bulletin of JSSD, Vol. 59 No. 4, pp. 39-44.

Kuijk, J. v, Heimrich, K., Christiaans, H. and Daan, v. E. (2007), "Usability in Product Development Practice: After Sales Information as Feedback.”, In Proceeding of IASDR07, Hongkong, China.

Martin, J.L., Norris, B.J., Murphy, E., and Crowe, J.A. (2008), "Medical Device Development: The challenge for Ergonomics". Applied Ergonomics. Vol. 30, pp. 271-283. http://doi.org/10.1016/j.apergo.2007.10.002.

MAUDE FDA database: https://www.accessdata.fda.gov/scripts/cdrh/cfdocs/cfmaude/search.cfm, Seen on 5 November 2018,

Norman, D. (1996), "Design as Practiced". Bringing Design to Software. T. Winograd, New York, USA, ACM Press.

Ouden, E.d. (2005), "Development of a Design Analysis Model for Consumer Complaints, Department of Technology Management", Section Product ND Process Quality. Eindhoven Technical University. PhD p. 165.

Quinones, D. and Rusu, C. (2016), "How to develop usability heuristics: A systematic literature review". Computer Standards \& Interfaces. Vol. 53, pp. 89-122. http://doi.org/10.1016/j.csi.2017.03.009.

Sauro, J. and Kindlund, E. (2005), "A Method to Standardize Usability Metrics into a Single score", Proceedings of SIGCHI Conference on Human Factors in Computing systems, pp 401-409. http://doi.org/10.1145/1054972.1055028

Shah, S.G.S. and Robinson, I. (2007), "Benefits of and barriers to involving users in medical device technology development and evaluation”. International Journal of Technology Assessment in Health Care, Vol. 23 No. 1, pp. 131-137. http://doi.org/10.1017/S026646230705167.

Shrestha, S., Abdinnour-Helm, S. and Chaparro, B.S. (2008), "Using the Analytic Hierarchical Process to Create a Single Usability Score for Website Interfaces", Proceedings of the Human Factors and Ergonomics Society Annual Meeting, Vol. 52 No. 16, pp. 1122-1126. http://doi.org/10.1177/154193120805201605.

Shorrock, T.S. and Williams, A.C. (2016), "Human Factors and Ergonomics methods in practice: Three fundamental constraints". Theoretical issues in Ergonomics Science, Vol. 17 No. 5-6, pp. 468-482. http://doi.org/10.1080/1463922X.2016.1193352 
Sun, X., Ploucher, T. and Qu, W. (2007), “An empirical study on the smallest Comfortable Button/Icon size on Touchscreen". Lecture Notes in Computer Science (including Subseries Lecture Notes in Artificial Intelligence and Lecture Notes in Bioinformatics), Vol. 4559 No. 1, pp. 615-621.

Tao, D., Yuan, J., Liu, Shuang and Qu, X., "Effect of Button Design Characteristics on performance and perceptions of Touchscreen Use". International Journal of Industrial Ergonomics, Vol. 64. pp. 59-68. http://doi.org/10.1016/j.ergon.2017.12.001

Vincent, C. and Blandford, A. (2011), "Designing for Safety and Usability: User centred Techniques in Medical Device Design Practice”. In Proceedings of Human Factors and Ergonomics Society. http://doi.org/10.1177/1071181311551164.

Wixon, D. (2003), "Evaluating usability methods: why the current literature fails the practitioner". Interactions, Vol. 10 No. 4, pp. 28-34. http://doi.org/10.1145/838830.838870

\section{ACKNOWLEDGEMENT}

We thank Ravivarman Ganesan, Human Factors Engineer, Jiang Cong, Systems Engineering Manager and Satish Kumar Gopalakrishnan, R\&D Director from Hill -Rom Services Pte. Ltd. for their support and encouragement during industry attachment with the company, which was a motivation to this paper. 